\title{
Model updating of strategic building structures under real earthquake loading
}

\author{
R. Ceravolo, A. De Stefano, E. Matta, A. Quattrone, L. Zanotti Fragonara \\ Department of Structural, Geotechnical and Building Engineering, Politecnico di Torino, 24 Corso Duca \\ degli Abruzzi, Torino, 10129, Italy
}

\begin{abstract}
Public buildings such as hospitals, schools, churches and city halls constitute an asset of strategic importance into the life of a community. The assessment of the safety conditions and the vulnerability to natural catastrophic events must be checked, also resorting to experimental techniques. The adoption of vibration monitoring procedures represents a particularly appealing perspective for existing structures. The growing use of permanent monitoring systems allows collecting data of the structural response during earthquakes. An invaluable tool for structural health monitoring and damage detection, parametric system identification through model-updating is an inverse problem, affected by several kinds of modelling assumptions and measurement errors. By minimizing the discrepancy between the measured data and the simulated response, traditional model-updating techniques identify one single optimal model that behaves similarly to the real structure.
\end{abstract}

\section{INTRODUCTION}

In the event of an earthquake, dynamic monitoring systems can supply precious information on the actual behaviour of existing buildings, allowing for the calibration of numerical models, which can be used for assessing the structural seismic safety as well as for designing possible rehabilitation interventions. In the latter connection, FE models are updated on an experimental basis from data supplied by the permanent monitoring system.

This concept has recently inspired the foundation, within the Italian Department of Civil Protection (DPC), of the Structures Seismic Observatory (OSS), a national-wide network for the permanent monitoring of the seismic response of more than one hundred strategic public buildings in Italy. This network allows a rapid evaluation of the damage induced by seismic actions on monitored structures and on neighbouring similar buildings, helping DPC in planning and managing emergency activities in the earthquake's aftermaths. The OSS network includes: (i) the primary sub-network, comprising 105 strategic public buildings (schools, hospitals and city halls), 10 bridges and a few dams, all intensely instrumented with a dynamic permanent monitoring system (16-32 accelerometers each), and (ii) the secondary sub-network, comprising 300 buildings, all equipped with a simplified monitoring system ( 7 accelerometers each).

Four of the buildings included in the main subnetwork, monitored during the Lunigiana/Garfagnana event (January 27th, 2012), have been selected as case studies in the framework of the inter-university Italian DPC-ReLUIS 2010-2013 Project, and commended to the Department of Structural, Geotechnical and Building Engineering at Politecnico di Torino, as a partner Unit, to the aim of dynamic characterization. This paper briefly introduces these four case studies and exemplifies the modal identification and model-updating procedure on one of them, namely the city hall of San Romano in Garfagnana.

\section{THE FOUR SELECTED CASE STUDIES}

The four case studies are listed in Table 1 and depicted in Figure 1. They have all been monitored by DPC during the seismic event which has stroked the Lunigiana/Garfagnana area on the 27th of January, 2012, whose synthetic properties are summarized in Table 2. For each of the four buildings, a dynamic identification has been performed using the acceleration data recorded during the said seismic event and a finite element (FE) model has been accordingly constructed and updated. For the sake of brevity, the identification and calibration procedure is exemplified in what follows for the first building only, i.e. the city hall of San Romano in Garfagnana.

Table 1. The four selected case-study buildings (buildings description provided in Figure 1).

\begin{tabular}{|c|c|c|c|c|}
\hline & $\begin{array}{l}\text { Building } \\
\text { (a) }\end{array}$ & $\begin{array}{l}\text { Building } \\
\text { (b) }\end{array}$ & $\begin{array}{l}\text { Building } \\
\text { (c) }\end{array}$ & $\begin{array}{l}\text { Building } \\
\text { (d) }\end{array}$ \\
\hline $\begin{array}{l}\text { Structural } \\
\text { typology }\end{array}$ & Masonry & $\begin{array}{l}\mathrm{RC} \\
\text { frames }\end{array}$ & $\begin{array}{l}\text { RC shear } \\
\text { walls }\end{array}$ & Masonry \\
\hline $\begin{array}{l}\text { Year of con- } \\
\text { struction }\end{array}$ & 1930 & 1972 & 1972 & $\begin{array}{l}1359 \text { (re- } \\
\text { built }\end{array}$ \\
\hline $\begin{array}{l}\text { Volume } \\
\left(\mathrm{m}^{3}\right)\end{array}$ & 2990 & 1687 & 7726 & $\begin{array}{l}1764 \\
9.5 \text { (bell }\end{array}$ \\
\hline $\begin{array}{l}\text { Height }(\mathrm{m}) \\
\text { Number of }\end{array}$ & 14.8 & 15.8 & 16.3 & tower 23 ) \\
\hline $\begin{array}{l}\text { sensors } \\
\text { PGA X (g) }\end{array}$ & $\begin{array}{l}20 \\
0.023\end{array}$ & $\begin{array}{l}16 \\
0.024\end{array}$ & $\begin{array}{l}22 \\
0.035\end{array}$ & $\begin{array}{l}26 \\
0.035\end{array}$ \\
\hline
\end{tabular}




\subsection{0}

0.053

Table 2. Synthetic parameters of the Lunigiana/Garfagnana event (27 Jan. 2012).

\begin{tabular}{lll}
\hline Epicenter & UTC Time & Magnitude \\
\hline Lat./long.: & $27 / 01 / 2012$ & 5.4 \\
$44.483^{\circ} / 10.033^{\circ}$ & & \\
Depth: $60 \mathrm{~km}$ & $14: 53: 14$ & \\
\hline
\end{tabular}
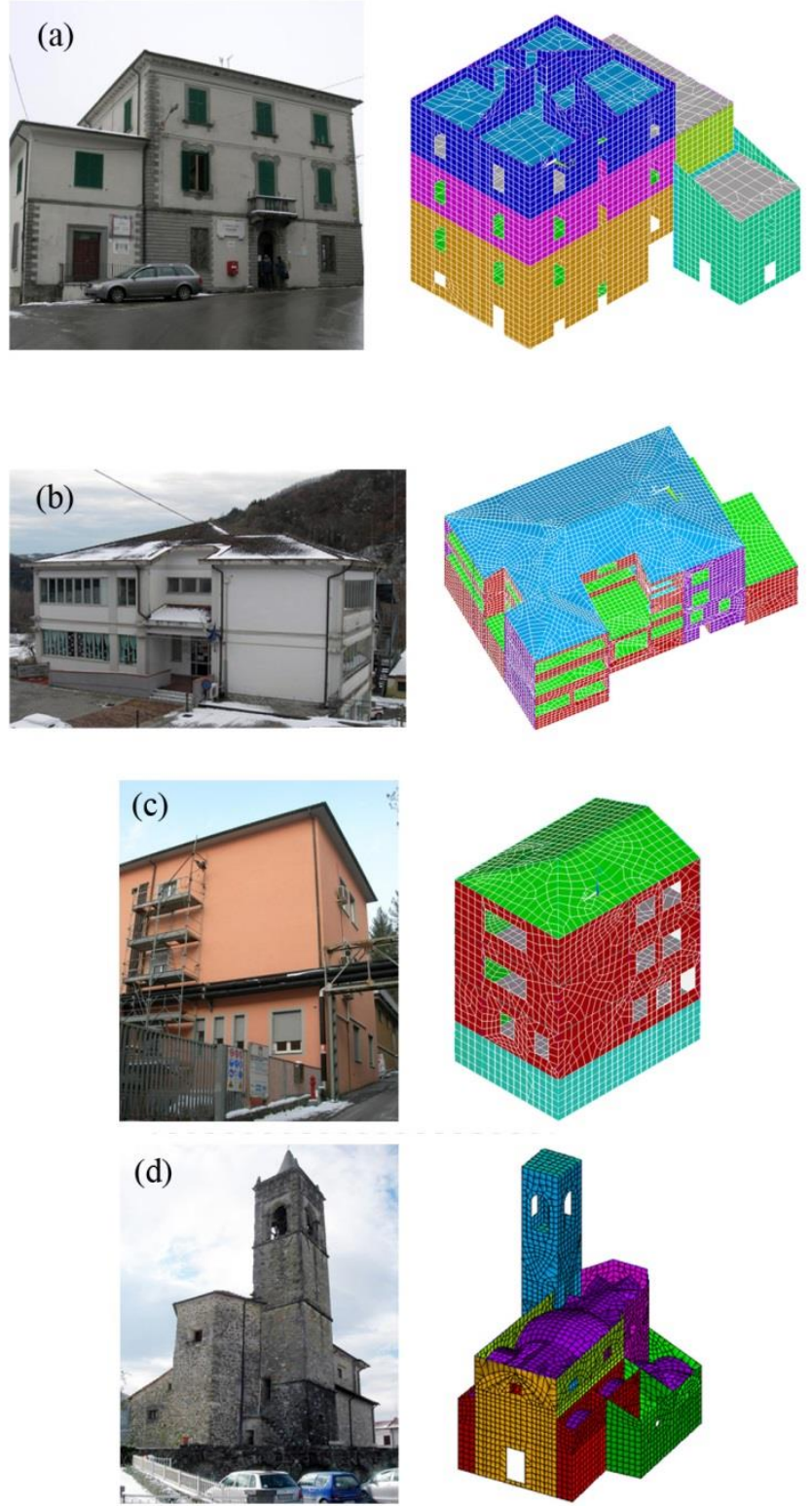

Figure 1. Four selected case-study buildings: (a) City hall of San Romano in Garfagnana ; (b) City hall of Casola in Lunigiana; (c) Hospital of Castelnuovo di Garfagnana; (d) Church of S. Caterina a Collegnago.

\section{THE CITY HALL OF SAN ROMANO IN GARFAGNANA}

Particular attention will be given in this paper to the case study of the city hall of San Romano in Garfagnana whilst the principal results will be listed for all the four buildings.

\subsection{The building}

San Romano in Garfagnana is located in a mediumto-high seismicity area (seismic zone 2 according to the OPCM 3274 Seismic Code, 2003). The city hall consists of a main building and two adjacent smaller units constructed at a later time (Figure 2a). The main building is a 4-storey masonry structure built on reinforced concrete foundations, having a $19.2 \times 11.4 \mathrm{~m}^{2}$ rectangular plan and a $14.8 \mathrm{~m}$ height. Built in the ' $30 \mathrm{~s}$, it was seismically and statically retrofitted in 1998. Foundations were sandwiched between new r.c. curbs, in order to achieve a more uniform distribution of soil pressures. Main masonry walls were plated with reinforced cement mortar, in order to increase shear strength. The original masonry walls distribution was recovered through reconstructing those elements which had been removed through the years. Floors were stiffened and strengthened, and their connection with masonry improved. In order to enhance structural regularity, a structural joint was realized between units 2 and 3, while units 1 and 2 were connected through steel bars' reinforcements inserted in adjacent walls. A survey on the mechanical properties of the constituent materials indicates a characteristic compressive strength of $115 \mathrm{MPa}$ for the stone blocks and of 7.2 MPa for the masonry panels.

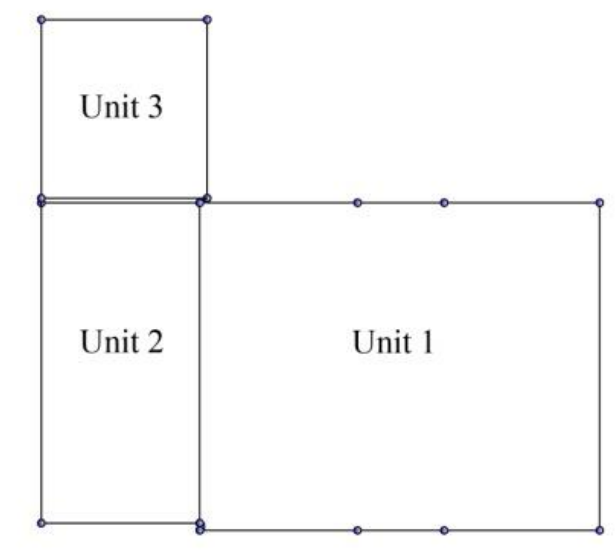

(a)

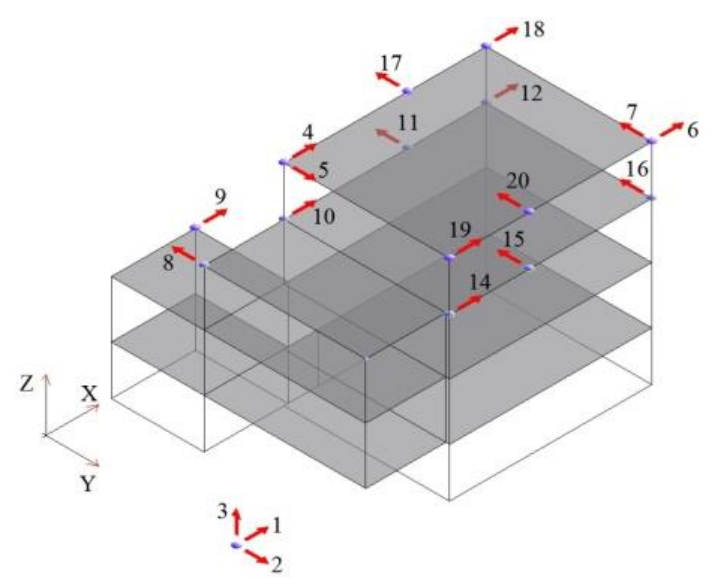

(b)

Figure 2. City Hall of San Romano in Garfagnana: (a) planar view; (b) sensors position and orientation 


\subsection{The monitoring system}

OSS permanent monitoring system consists of 20 force-balance uniaxial accelerometers. 17 accelerometers are installed along the building height and the remaining 3 accelerometers, constituting the ground reference channels, are placed inside an underground inspection hole. The position and orientation of the sensors are shown in Figure 2b. Among the 17 accelerometers deployed along the elevation, 16 are installed in units 2 and 3 (attached to the floors at the first and second levels) and only one is deployed in unit 3 (along the $\mathrm{X}$ direction). The acquisition system incorporates an $\mathrm{AD}$ converter and is connected with a GPS receiver for synchronization with the international UTC time.

\section{THE NUMERICAL MODEL}

For each building analyzed, based on original archive documentation a preliminary model has been constructed in order to highlight possible critical issues in the structural dynamic response and help interpreting processed signals. The structural members have been modeled using mono and bi-dimensional finite elements and adopting linear, elastic and isotropic material properties.

In details, the model of the city hall of San Romano in Garfagnana model consists of bi-dimensional plate- and shell-type finite elements grouped in macro-elements. The wooden roof has been modeled only in terms of its inertial contribution, as a uniformly distributed mass on the beams which crown the masonry walls.

Masonry properties have been deduced partly from destructive and non-destructive tests and partly from typical values suggested by the literature and by current Italian codes, depending on the outcome of visual inspections. In order to simply account for soil-structure interaction, the structural nodes are clamped at the foundation level and the stiffness of the underground wall elements is initially increased. The efficacy of the structural joint located between units 1 and 3 is highly uncertain because of the lack of documental information and because of the presence of only one sensor in unit 3. The joint is therefore modeled as a stripe of shell elements with reduced equivalent stiffness.

\section{DATA ACQUISITION AND MODELLING}

Dynamic identification from signals recorded during the seismic event requires that the input spectral components be distinguished from structural frequencies. In the assumption that the three ground reference signals reflect the input load into the dynamic system, the dominant earthquake components can be easily identified, helping with the estimated transfer functions and coherence functions.

\subsection{Data acquisition and pre-processing}

The analyzed experimental data are represented by the 20 acceleration signals recorded during the Lunigiana/Garfagnana earthquake. Figure 3 reports the time history and the acceleration spectra of the three input components, as recorded by the three ground reference sensors, respectively along the $\mathrm{X}$, $\mathrm{Y}$ and $\mathrm{Z}$ directions. The seismic energy content appears to be mostly concentrated in the $2-7 \mathrm{~Hz}$ frequency band. Dynamic identification from signals recorded during the seismic event requires that the input spectral components be distinguished from structural frequencies. In the assumption that the three ground reference signals reflect the input load into the dynamic system, the dominant earthquake components can be easily identified.
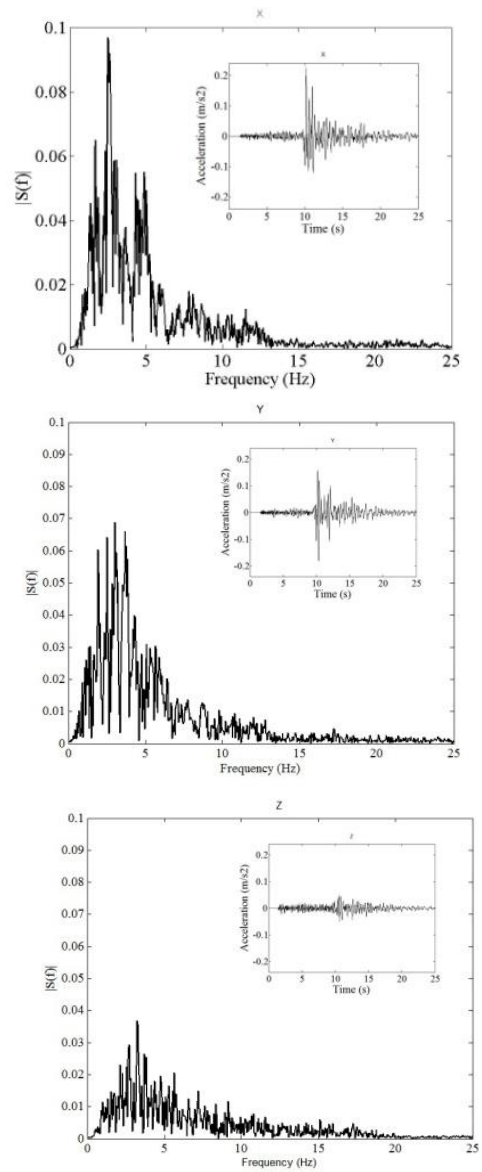

Figure 3. Acceleration spectra (and time-histories) of the three input components.

\subsection{Experimental modal analysis}

Structural modal identification has been conducted through applying an algorithm belonging to the family of SSI (Stochastic Subspace Identification) (Peeters \& DeRoeck, 1999; Larimore 1990), implemented in the SDIT3 code (Ceravolo \& Abbiati, 2013). 


\subsection{Dynamic identification procedure}

The identification algorithm has been applied to the output signals through progressively increasing the system order. In order to discriminate between real structural modes and spurious numerical modes the following stabilization criteria have been applied: (i) frequency variation < 2\%; (ii) damping variation < 15\%; (iii) damping ratio values comprised between $0 \%$ and 10\%; (iv) MAC (Modal Assurance Criterion) $>95 \%$ (Allemang 2002). Stabilization and frequency-damping clustering diagrams are reported in Figure 4. The seismic dominant frequency components, apparent in the stabilization diagram, have been subsequently identified and excluded from the model-updating procedure. The resulting identified frequencies and damping ratios for all the four buildings are reported in Table 3.

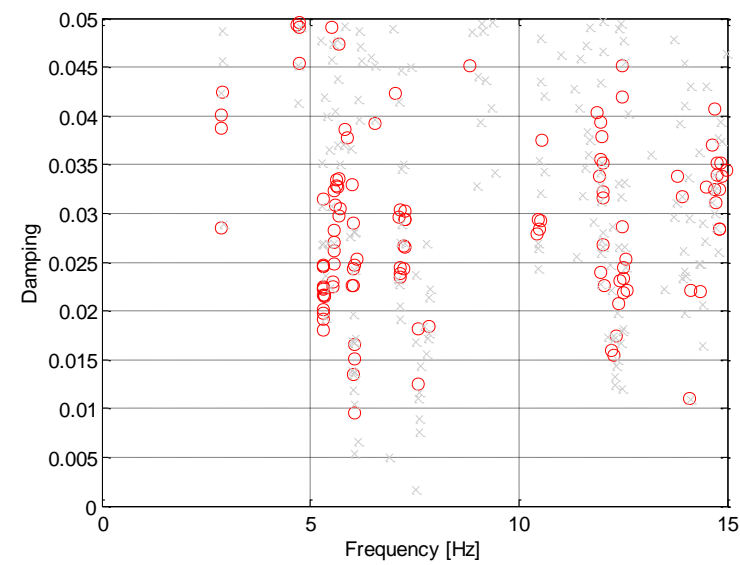

Figure 4. Example of Frequency-damping clustering diagram for the City Hall of San Romano.

Table 3. Modal frequencies and damping ratios identified through SSI for the four case studies.

\begin{tabular}{llll}
\hline Mode & f $(\mathrm{Hz})$ & $\zeta(\%)$ & Mode type \\
\hline & CITY HALL OF SAN ROMANO \\
\hline 1 & 5.32 & 1.8 & $1^{\text {st }}$ flexural along Y \\
2 & 6.08 & 1.8 & $1^{\text {st }}$ flexural along X \\
3 & 7.17 & 2.9 & $1^{\text {st }}$ torsional \\
4 & 11.98 & 3.6 & Local mode \\
5 & 15.65 & 1.5 & $2^{\text {nd }}$ torsional \\
\hline \multicolumn{4}{c}{ CITY HALL OF CASOLA } \\
\hline 1 & 5.85 & 1.0 & $1^{\text {st }}$ flexural along X \\
2 & 6.36 & 1.7 & $1^{\text {st }}$ flexural along Y \\
3 & 7.90 & 2.2 & $1^{\text {st }}$ torsional \\
\hline \multicolumn{4}{c}{ HOSPITAL OF CASTELNUOVO DI GARFAGNANA } \\
\hline 1 & 3.53 & 1.0 & $1^{\text {st }}$ flex. X, bell tower \\
2 & 6.52 & 1.7 & $1^{\text {st }}$ flex. Y, bell tower \\
3 & 7.68 & 2.2 & $2^{\text {nd }}$ flex. X, global \\
\hline \multicolumn{5}{c}{ CHURCH OF S.CATERINA } \\
\hline 1 & 1.97 & 3.0 & $1^{\text {st }}$ flex. X, bell tower \\
2 & 2.63 & 1.6 & $1^{\text {st }}$ flex. Y, bell tower \\
3 & 3.41 & 3.0 & $2^{\text {nd }}$ flex. X, global \\
4 & 4.20 & 4.0 & $1^{\text {st }}$ torsional, bell tower \\
5 & 4.40 & 1.6 & $2^{\text {nd }}$ flex. Y, global \\
\hline
\end{tabular}

Identified mode-shapes 1 to 4 of the city hall of San Romano are represented in Figure 5. It is worth noting that unit 3 seems not significantly involved in the first global modes but provides the largest displacement component in the fourth mode, which is therefore labeled as a local mode. This suggests a very limited participation of this unit to the overall dynamics of the building, and consequently a substantial efficacy of the uncertain structural joint between units 1 and 3.
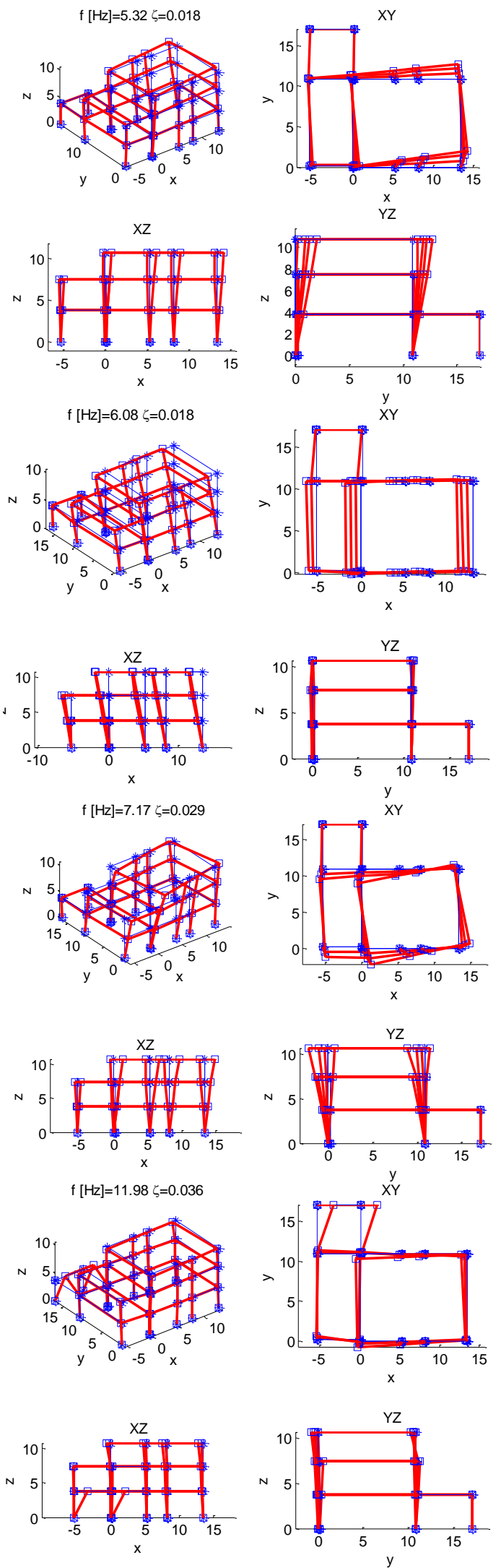

Figure 5. Identified mode-shapes: (a) mode 1 - 1st flexural along Y; (b) mode 2 - 1st flexural along X; (c) mode 3 - 1st torsional; (d) mode 4 - local mode. 
The updating procedure adopted consists in three main steps:

- Discretization of the FE model in homogeneous zones, to reduce the numbers of updating variables;

- Sensitivity analysis, to choose the most influencing parameters involved in the overall dynamic behavior;

- Minimization of error function, updating the parameters so that the analytical modal model would match the experimental modal model.

\subsection{Discretization of the FE model}

Depending on the different age and type of the main parts of the three units, a total of 17 materials (linear elastic and isotropic) are preliminary identified in the baseline model. In order to reduce the number of updating variables, parameters which are likely to be less uncertain and less influential on the global dynamic behavior are excluded from updating. The model is therefore parted in the 6 homogeneous zones represented in Figure 6a. The structural joint between units 1 and 3 is one of them, its nominal value having been manually calibrated to $0.10 \mathrm{GPa}$ in order for the analytical modes' sequence to match the experimental one.

\subsection{Objective function and sensitivity analysis}

The objective (or error) function selected for updating, and therefore used for the sensitivity analysis as well, is defined as (Friswell \& Mottershead 1995):

$\varepsilon(\mathbf{x})=\sum_{i=1}^{m}\left[\alpha_{i}\left(\frac{f_{a i}-f_{e i}}{f_{e i}}\right)^{2}+\beta\left(\frac{1-\sqrt{M A C_{i}}}{M A C_{i}}\right)\right]$

where $\mathbf{x}$ is the updating parameter vector, $f_{a i}$ and $f_{e i}$ are the analytical and experimental $\mathrm{i}$-th natural frequencies, $\mathrm{MAC}_{\mathrm{i}}$ is the Modal Assurance Criterion between the i-th identified mode-shape and the corresponding $i$-th analytical mode-shape, $\alpha \mathrm{i}$ and $\beta \mathrm{i}$ are the weight factors for the frequency and the modeshape errors, respectively.

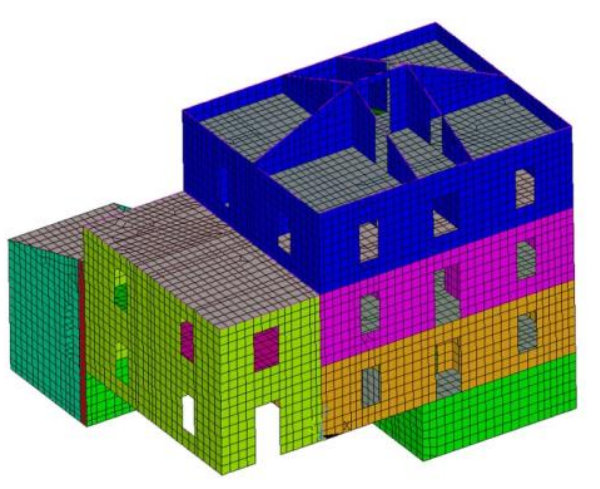

Figure 6a. FE model discretization in 6 homogeneous zones.

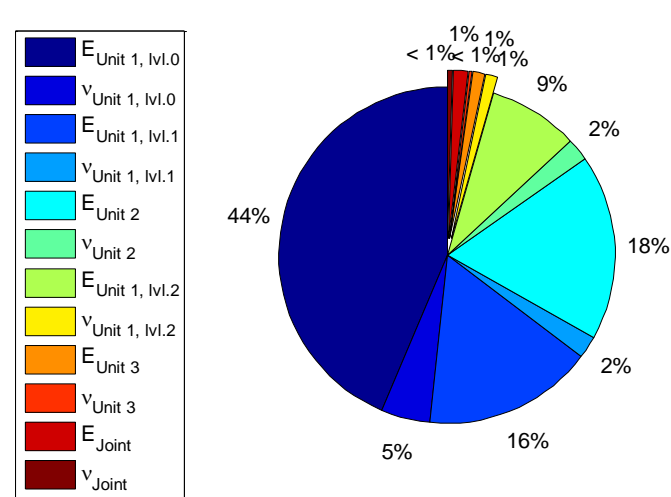

Figure 6b. Sensitivity indexes.

The sensitivity analysis is based on the local sensitivity index defined by Saltelli et al. (2000) as:

$$
\hat{S}_{i}=\frac{\ln (\varepsilon)-\ln \left(\varepsilon_{0}\right)}{\ln \left(x_{i}\right)-\ln \left(x_{i 0}\right)}
$$

where $\mathrm{x}_{\mathrm{i} 0}$ and $\mathrm{x}_{\mathrm{i}}=\mathrm{x}_{\mathrm{i} 0} \cdot(1+\delta)$ are, respectively, the initial nominal value of the $\mathrm{i}$-th updating parameter and its value incremented of a given percentage $\delta$ (here assumed equal to $5 \%), \varepsilon_{0}$ is the error corresponding to the nominal model, and $\varepsilon$ is the error corresponding to equaling all parameters to their nominal value while setting the $\mathrm{i}$-th parameter to $\mathrm{x}_{\mathrm{i}}$.

Expressed in terms of percentage values, the relative sensitivity index is reported in Figure $6 \mathrm{~b}$. The elastic modulus of the lower stories appears clearly predominant.

Based on the sensitivity analysis, the four most significant parameters have been chosen as the updating parameters. For the city hall of San Romano, these parameters are summarized in Table 4, with their initial nominal values reported in the second column.

Table 4. Updating elastic moduli of the city hall of San Romano. Second column: nominal values. Third column: updated values

\begin{tabular}{lcc}
\hline Part & Initial E (GPa) & Updated E (GPa) \\
\hline $\begin{array}{l}\text { 1) Masonry of unit 1 } \\
\text { Level 0 }\end{array}$ & 1.50 & 1.84 \\
$\begin{array}{l}\text { 2) Masonry of unit 1 } \\
\text { Level 1 }\end{array}$ & 1.50 & 1.60 \\
$\begin{array}{l}\text { 3) Masonry of unit 1 }- \\
\text { Level 2 }\end{array}$ & 1.50 & 1.03 \\
4) Masonry of unit 2 & 1.50 & 0.78 \\
\hline
\end{tabular}

In this case, the model-updating procedure has consisted in the numerical minimization of the objective function $\varepsilon$ in Eq.(1) by means of a genetic algorithm, using 15 generations and a population of 300 individuals. Weights $\alpha_{i}$ and $\beta_{i}$ are taken as 0.8 and 0.2 , as suggested by Merce et al. (2007). The updated values of the five selected parameters are reported in the third column of Table 4.

The optimal solution is reported in Table 5, which is referred to the four monitored building. A satisfactory agreement between the analytical and the exper- 
imental modal models can be appreciated. MAC values between analytical and identified modes, in particular, are always greater than $80 \%$. The first mode-shapes of the updated model are reported in Figure 7 for the building in San Romano. Figure 8 reports the first three vibration modes resulting from the updated model of the hospital monitored in Castelnuovo.

Table 5. Updated natural frequencies and frequency errors for the four different buildings.

\begin{tabular}{|c|c|c|c|}
\hline Mode & Frequency $(\mathrm{Hz})$ & $\Delta \mathrm{f}(\%)$ & MAC \\
\hline \multicolumn{4}{|c|}{ CITY HALL OF SAN ROMANO } \\
\hline 1 & 5.39 & $1.3 \%$ & $93 \%$ \\
\hline 2 & 5.76 & $-5.3 \%$ & $91 \%$ \\
\hline 3 & 7.56 & $5.4 \%$ & $82 \%$ \\
\hline 4 & 11.73 & $-2.1 \%$ & $82 \%$ \\
\hline \multicolumn{4}{|c|}{ CITY HALL OF CASOLA } \\
\hline 1 & 5.41 & $-8.1 \%$ & $88 \%$ \\
\hline 2 & 5.62 & $-12.1 \%$ & $85 \%$ \\
\hline 3 & 8.45 & $6.5 \%$ & $91 \%$ \\
\hline \multicolumn{4}{|c|}{ HOSPITAL OF CASTELNUOVO DI GARFAGNANA } \\
\hline 1 & 3.75 & $0.3 \%$ & $99 \%$ \\
\hline 2 & 6.39 & $-3.3 \%$ & $94 \%$ \\
\hline 3 & 7.74 & $-1.0 \%$ & $92 \%$ \\
\hline \multicolumn{4}{|c|}{ CHURCH OF S.CATERINA } \\
\hline 1 & 2.00 & $1.5 \%$ & $98 \%$ \\
\hline 2 & 2.49 & $-5.6 \%$ & $95 \%$ \\
\hline 3 & 3.61 & $5.5 \%$ & $88 \%$ \\
\hline
\end{tabular}

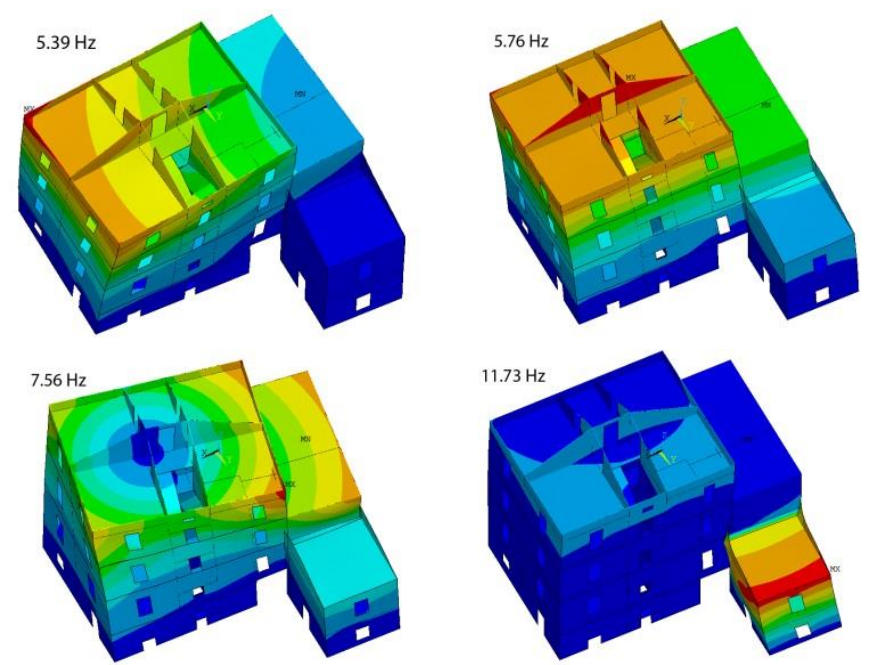

Figure 7. Mode shapes of the updated model of the city hall of San Romano.
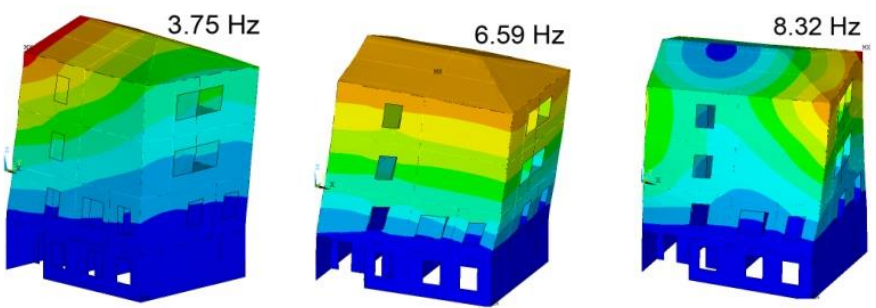

Figure 8. Mode shapes of the updated model of the hospital of Castelnuovo.

\section{CONCLUSIONS}

The experimental dynamic identification of four strategic building belonging to the OSS permanent seismic monitoring network is here reported as an example of a larger pilot study including a total of four public buildings monitored during a recent earthquake. The study provides useful indications on how to design monitoring actions and experimentally updated numerical model which can be of help in assessing the current structural seismic safety and in planning future interventions.

\section{ACKNOWLEDGEMENTS}

This research has been conducted within the activities of inter-university Italian DPC-ReLUIS 2010-2013 Project - Research line n. 1 "Development of Technologies for Monitoring and Management of the Seismic Risk".

\section{REFERENCES}

Allemang, R.J. 2002. The Modal Assurance Criterion (MAC): twenty years of use and abuse. Proceeding of 20th International Modal Analysis Conference. Los Angeles, CA.

Ceravolo, R. and Abbiati, G. 2013. Time Domain Identification of structures: a Comparative Analysis. ASCE Journal of Engineering Mechanics.

Friswell, M.I. and Mottershead, J.E. 1995. Finite Element Model Updating in Structural Dynamics. Kluwer Academic Publishers.

Larimore, W.E. 1990. Canonical Variate Analysis. Proceedings of the 29th IEEE Conference on Decision and Control. Honolulu, Hawaii.

Merce, R.N., Doz, G.N., Vital de Brito, J.L., Macdonald, J.H. and Friswell, M.I. 2007. Finite element model updating of a suspension bridge. Design and Optimization Symposium. Florida, USA.

Peeters, B. and DeRoeck, G. 1999. Referencebased stochastic subspace identification for outputonly modal analysis. Mechanical Systems and Signal Processing 13: 855-878.

Saltelli, A., Chan, K. and Scott, E.M. 2000. Sensitivity Analysis. Chirchester (UK): Wiley. 
2013-12-31

\section{Model updating of strategic building} structures under real earthquake loading

Ceravolo, Rosario

CRC Press

Rosario Ceravolo, Emiliano Matta, Antonino Quattrone, Luca Zanotti Fragonara and Alessandro

De Stefano. Model updating of strategic building structures under real earthquake loading.

Proceedings of the Fifth International conference on structural engineering, mechanics and computation, 2-4 September 2013, Cape Town, South Africa.

https://dspace.lib.cranfield.ac.uk/handle/1826/12254

Downloaded from Cranfield Library Services E-Repository 